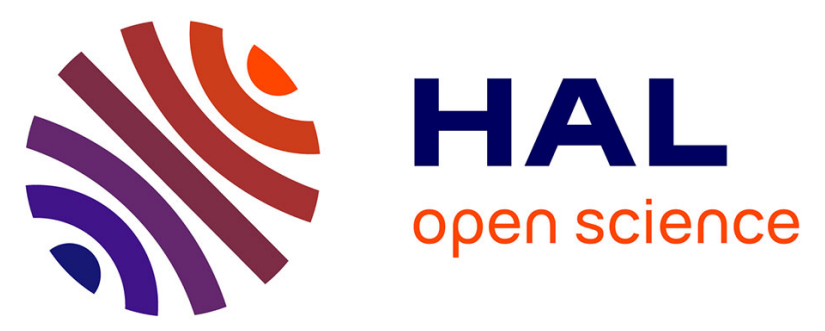

\title{
N2O-mediated propane oxidative dehydrogenation over Fe-zeolites. TEOM studies for continuous propylene production in a cyclically-operated reactor
}

Javier Peŕez-Ramírez, Amalia Gallardo-Llamas, C. Daniel, Claude Mirodatos

\section{- To cite this version:}

Javier Peŕez-Ramírez, Amalia Gallardo-Llamas, C. Daniel, Claude Mirodatos. N2O-mediated propane oxidative dehydrogenation over Fe-zeolites. TEOM studies for continuous propylene production in a cyclically-operated reactor. Chemical Engineering Science, 2004, 59 (22-23), pp.5535-5543. 10.1016/j.ces.2004.07.035 . hal-00007469

\section{HAL Id: hal-00007469 \\ https://hal.science/hal-00007469}

Submitted on 13 Aug 2021

HAL is a multi-disciplinary open access archive for the deposit and dissemination of scientific research documents, whether they are published or not. The documents may come from teaching and research institutions in France or abroad, or from public or private research centers.
L'archive ouverte pluridisciplinaire HAL, est destinée au dépôt et à la diffusion de documents scientifiques de niveau recherche, publiés ou non, émanant des établissements d'enseignement et de recherche français ou étrangers, des laboratoires publics ou privés.

\section{(c)(1)}

Distributed under a Creative Commons Attribution| 4.0 International License 


\title{
$\mathrm{N}_{2} \mathrm{O}$-mediated propane oxidative dehydrogenation over Fe-zeolites. TEOM studies for continuous propylene production in a cyclically-operated reactor
}

\author{
J. Pérez-Ramírez ${ }^{\mathrm{a}, *}$, A. Gallardo-Llamas ${ }^{\mathrm{a}}$, C. Daniel ${ }^{\mathrm{b}}$, C. Mirodatos ${ }^{\mathrm{b}}$ \\ ${ }^{a}$ Yara Technology Centre Porsgrunn, Catalysis and Nitric Acid Technology, P.O. Box 2560, N-3908, Porsgrunn, Norway \\ ${ }^{\mathrm{b}}$ Institut de Recherches sur la Catalyse, CNRS 2, Avenue Albert Einstein, F-69626, Villeurbanne Cedex, France
}

\begin{abstract}
Steam-activated iron-zeolites (FeZSM-5, Fe-silicalite, Fe-beta) are highly efficient catalysts for the oxidative dehydrogenation of propane using $\mathrm{N}_{2} \mathrm{O}$, with initial propene yields up to $25 \%$ at $723 \mathrm{~K}$, but they deactivate due to coking. Since catalyst deactivation is reversible, the feasibility of a cyclically-operated process for continuous propene production, with alternation of reaction and regeneration cycles, has been analysed. In order to rationally design the sequence in the cyclic experiments, a tapered element oscillating microbalance (TEOM) coupled to on-line analysis of products has been applied. The TEOM provides information on activity, deactivation, and regeneration by simultaneous measurement of reaction and mass changes. In a system with two fixed-bed reactors in parallel using FeZSM-5, stable propene yields $>20 \%$ were obtained during cycling for $2000 \mathrm{~min}$, using reaction and regeneration temperatures of 723 and $823 \mathrm{~K}$, respectively. This catalytic process leads to the simultaneous valorization of $\mathrm{C}_{3} \mathrm{H}_{8}$ and $\mathrm{N}_{2} \mathrm{O}$ and can be economically applied for on-site propylene production using a low-cost source of $\mathrm{N}_{2} \mathrm{O}$, e.g. in tail-gases of chemical processes where $\mathrm{N}_{2} \mathrm{O}$ is produced in high concentration.
\end{abstract}

Keywords: Catalysis; Catalyst deactivation; Zeolites; Chemical reactors; Oxidative dehydrogenation; Cyclic operation; TEOM

\section{Introduction}

Propylene is mainly produced as a co-product in ethylene steam crackers and gasoline-making fluidized catalytic crackers. However, the growing demand of this olefin in the modern petrochemical industry requires the development of on-purpose propylene technologies, such as propane dehydrogenation and metathesis of ethylene and butylene, which currently account for $2-3 \%$ of the global production (Tullo, 2003). Many recent studies have explored the catalytic oxidative dehydrogenation of light alkanes as a potential route to the corresponding alkenes. For the oxidative dehydrogenation of propane (ODHP), promising formulations are based on modified $\mathrm{V}$ and Mo oxides, with propene yields

\footnotetext{
* Corresponding author. Tel.: +47-24-15-8518; fax: +47-24-15-8213.
}

E-mail address: javier.perez.ramirez@yara.com (J. Pérez-Ramírez). in the range of 10-30\% using $\mathrm{O}_{2}$ as the oxidant (Watson and Ozkan, 2000; Liu et al., 2001; Buyevskaya and Baerns, 2002; Pak et al., 2002).

A recent study has shown the superior performance of steam-activated $\mathrm{Fe}$-zeolites in the $\mathrm{N}_{2} \mathrm{O}$-mediated propane oxidative dehydrogenation, Eq. (1) (Pérez-Ramírez and Kondratenko, 2003; Pérez-Ramírez and Gallardo-Llamas, 2004). Initial propene yields of $24 \%$ at $773-798 \mathrm{~K}$ were achieved, comparable with the highest values reported over $\mathrm{V}$ and Mo-based catalysts with $\mathrm{O}_{2}$. This reaction leads to the functionalization of propane, a relatively cheap and abundant feedstock, and utilization of $\mathrm{N}_{2} \mathrm{O}$, an environmentally harmful gas. The remarkable performance of Fe-zeolites has been related to the specificity of $\mathrm{N}_{2} \mathrm{O}$ as a monooxygen donor and the capability of determined iron forms in the zeolite for coordinating reactive atomic oxygen species able to efficiently dehydrogenate propane 
(Pérez-Ramírez and Gallardo-Llamas, 2004). A major drawback of Fe-zeolites in ODHP with $\mathrm{N}_{2} \mathrm{O}$ is the deactivation by coke. This causes a rapid decrease of the propene yield, although the original catalytic activity was completely recovered after regeneration in pure oxygen at $773 \mathrm{~K}$ for $30 \mathrm{~min}$ (Pérez-Ramírez and Kondratenko, 2003).

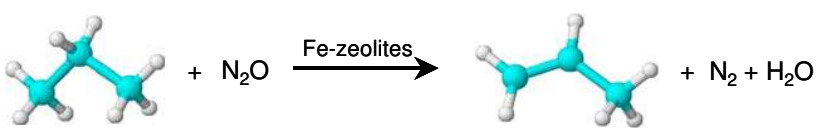

On this basis, the present work was undertaken to evaluate the feasibility of a cyclically-operated process for continuous $\mathrm{C}_{3} \mathrm{H}_{6}$ production via ODHP with $\mathrm{N}_{2} \mathrm{O}$ using Fe-zeolites. This was achieved in a configuration of two fixed-bed reactors in parallel with alternation of reaction and regeneration steps. The tapered element oscillating microbalance (TEOM) technique was applied to evaluate catalytic performance, deactivation, and regeneration, in order to rationally design the cyclic process.

\section{Experimental}

\subsection{Catalysts}

The hydrothermal syntheses of FeZSM-5, Fe-silicalite, and Fe-beta have been described elsewhere (Pérez-Ramírez et al., 2002, 2003; Pérez-Ramírez and Gallardo-Llamas, 2004). The as-synthesized samples were calcined in air and activated in flowing steam $\left(30 \mathrm{vol} \% \mathrm{H}_{2} \mathrm{O}\right.$ and $30 \mathrm{mlSTP} \min ^{-1}$ of $\mathrm{N}_{2}$ ) at ambient pressure and $873 \mathrm{~K}$ during $5 \mathrm{~h}$. The iron content in the samples is very similar (Table 1), enabling a direct comparison of catalytic performances.

\subsection{TEOM studies}

Reaction, coke deactivation, and regeneration studies were carried out in a Rupprecht and Patashnick TEOM 1500 pulse mass analyser (Fig. 1). The TEOM consists of a microreactor $(4 \mathrm{~mm}$ i.d.) with a high-resolution microbalance that generates real-time measurements of mass changes during gas-solid reactions (Chen et al., 1996; Zhu et al., 1998; Gembicki et al., 2003). The TEOM microbalance measures mass changes based on inertial forces, presenting various key advantages over conventional gravimetric microbalances: (i) a well-defined flow profile, eliminating possible (heat and mass) diffusion and buoyancy phenomena, (ii) a very fast response time resolution $(0.1 \mathrm{~s})$, and (iii) a high mass resolution across the entire range of pressure and temperature.

The TEOM reactor was loaded with $30 \mathrm{mg}$ of catalyst (sieve fraction 125-200 $\mu \mathrm{m}$ ), firmly packed between two plugs of quartz wool. Prior to experiments the catalysts were pretreated in flowing $\mathrm{He}$ at the reaction temperature for $2 \mathrm{~h}$. When stable baseline was reached, He was replaced by the reaction mixture, and mass changes and product gases were continuously monitored. Equal flows of purge gas $(\mathrm{He})$ and reaction gas of $200 \mathrm{ml} \mathrm{min}^{-1}$ were used (see Fig. 1) and the feed gases were pretreated at $423 \mathrm{~K}$. The ODHP with $\mathrm{N}_{2} \mathrm{O}$ was carried out at $673-773 \mathrm{~K}$ in a mixture of 100 mbar $\mathrm{C}_{3} \mathrm{H}_{8}$ and 100 mbar $\mathrm{N}_{2} \mathrm{O}$ in $\mathrm{He}$ at a total pressure of $P=2$ bar and a weight-hourly space velocity (WHSV) of $400,000 \mathrm{ml} \mathrm{h}^{-1} \mathrm{~g}_{\text {cat }}^{-1}$. The coke content $\left(C_{\text {coke }}\right)$ was determined from the mass change measured during reaction, accounting for the mass change caused by the change of gas density in the tapered element when He was replaced by the reaction mixture. The product gases were analysed by an on-line micro-GC (Chrompack CP-2002) equipped with a TCD, using Poraplot Q and Molsieve 5A columns.

Regeneration of the coked zeolites in air $\left(200 \mathrm{ml} \mathrm{min}^{-1}\right)$ was investigated by following mass changes in two ways:

Table 1

Catalysts investigated in this study and reaction parameters during ODHP with $\mathrm{N}_{2} \mathrm{O}$. Conditions as in caption of Fig. 4

\begin{tabular}{|c|c|c|c|c|c|c|c|c|c|c|c|}
\hline \multirow[t]{2}{*}{ Catalyst } & \multirow[t]{2}{*}{$\mathrm{Si} / \mathrm{Al}^{\mathrm{a}}$} & \multirow[t]{2}{*}{$\mathrm{Fe}^{\mathrm{a}} / \mathrm{wt} \%$} & \multirow[t]{2}{*}{$\mathrm{T} / \mathrm{K}$} & \multicolumn{2}{|c|}{$\mathrm{X}\left(\mathrm{N}_{2} \mathrm{O}\right)^{\mathrm{d}} / \%$} & \multicolumn{2}{|c|}{$\mathrm{X}\left(\mathrm{C}_{3} \mathrm{H}_{8}\right)^{\mathrm{d}} / \%$} & \multicolumn{2}{|c|}{$\mathrm{Y}\left(\mathrm{C}_{3} \mathrm{H}_{6}\right)^{\mathrm{c}} / \%$} & \multirow{2}{*}{$\frac{\mathrm{S}\left(\mathrm{C}_{3} \mathrm{H}_{6}\right)^{\mathrm{e}} / \%}{\mathrm{t}_{\mathrm{o}}}$} & \multirow{2}{*}{$\frac{C_{\text {coke }}^{\mathrm{f}} / \mathrm{wt} \%}{\mathrm{t}_{f}}$} \\
\hline & & & & $t_{0}^{b}$ & $\mathrm{t}_{f} \mathrm{c}$ & $t_{0}$ & $\mathrm{t}_{f}$ & $t_{0}$ & $\mathrm{t}_{f}$ & & \\
\hline Fe-beta & 31.8 & 0.61 & 723 & 99 & 7 & 45 & 0 & 19 & 0 & 42 & 9.2 \\
\hline \multirow[t]{2}{*}{ Fe-silicalite } & $\infty$ & 0.68 & 723 & 98 & 12 & 42 & 3 & 22 & 2 & 52 & 7.6 \\
\hline & & & 723 & 96 & 25 & 48 & 10 & 22 & 9 & 46 & 20.0 \\
\hline \multirow[t]{2}{*}{ FeZSM-5 } & 31.3 & 0.67 & 673 & 76 & 15 & 40 & 6 & 20 & 8 & 50 & 6.9 \\
\hline & & & 773 & 100 & 72 & 48 & 16 & 21 & 9 & 43 & 22.7 \\
\hline
\end{tabular}

${ }^{\mathrm{a}}$ Chemical composition determined by ICP-OES.

$\mathrm{b}_{\mathrm{t}_{\mathrm{o}}}$ : initial activity (after 2 min on stream).

$\mathrm{c}_{\mathrm{t}_{f}}$ : reaction parameters after $400 \mathrm{~min}$ on stream.

${ }^{d} \mathrm{~N}_{2} \mathrm{O}$ and $\mathrm{C}_{3} \mathrm{H}_{8}$ conversions were calculated from the amount of $\mathrm{N}_{2}$ formed and $\mathrm{C}_{3} \mathrm{H}_{8}$ reacted, respectively.

${ }^{e}$ Propene yield and selectivity were calculated as $\mathrm{Y}\left(\mathrm{C}_{3} \mathrm{H}_{6}\right)=\mathrm{C}\left(\mathrm{C}_{3} \mathrm{H}_{6}\right) / \mathrm{C}^{\mathrm{o}}\left(\mathrm{C}_{3} \mathrm{H}_{8}\right)$ and $\mathrm{S}\left(\mathrm{C}_{3} \mathrm{H}_{6}\right)=\mathrm{Y}_{(}\left(\mathrm{C}_{3} \mathrm{H}_{6}\right) / \mathrm{X}\left(\mathrm{C}_{3} \mathrm{H}_{8}\right)$, respectively, where $\mathrm{C}\left(\mathrm{C}_{3} \mathrm{H}_{6}\right)$ is the outlet propene concentration at a certain time, $\mathrm{C}^{\mathrm{O}}\left(\mathrm{C}_{3} \mathrm{H}_{8}\right)$ is the inlet concentration of propane, and $\mathrm{X}\left(\mathrm{C}_{3} \mathrm{H}_{8}\right)$ is the conversion of propane.

${ }^{\mathrm{f}}$ Coke content determined as $\mathrm{C}_{\text {coke }}=\Delta \mathrm{m}_{\text {coke }} / \mathrm{m}_{\mathrm{o}}=\left(\Delta \mathrm{m}_{t}-\Delta \mathrm{m}_{d}\right) / \mathrm{m}_{\mathrm{o}}$, where $\mathrm{m}_{\mathrm{o}}$ is the initial sample amount. The total mass uptake $\Delta \mathrm{m}_{t}$ measured by the TEOM includes the amount of coke formed $\left(\Delta \mathrm{m}_{\text {coke }}\right)$ and the mass change of the gas density in the tapered element $\left(\Delta \mathrm{m}_{\mathrm{d}}\right)$. 

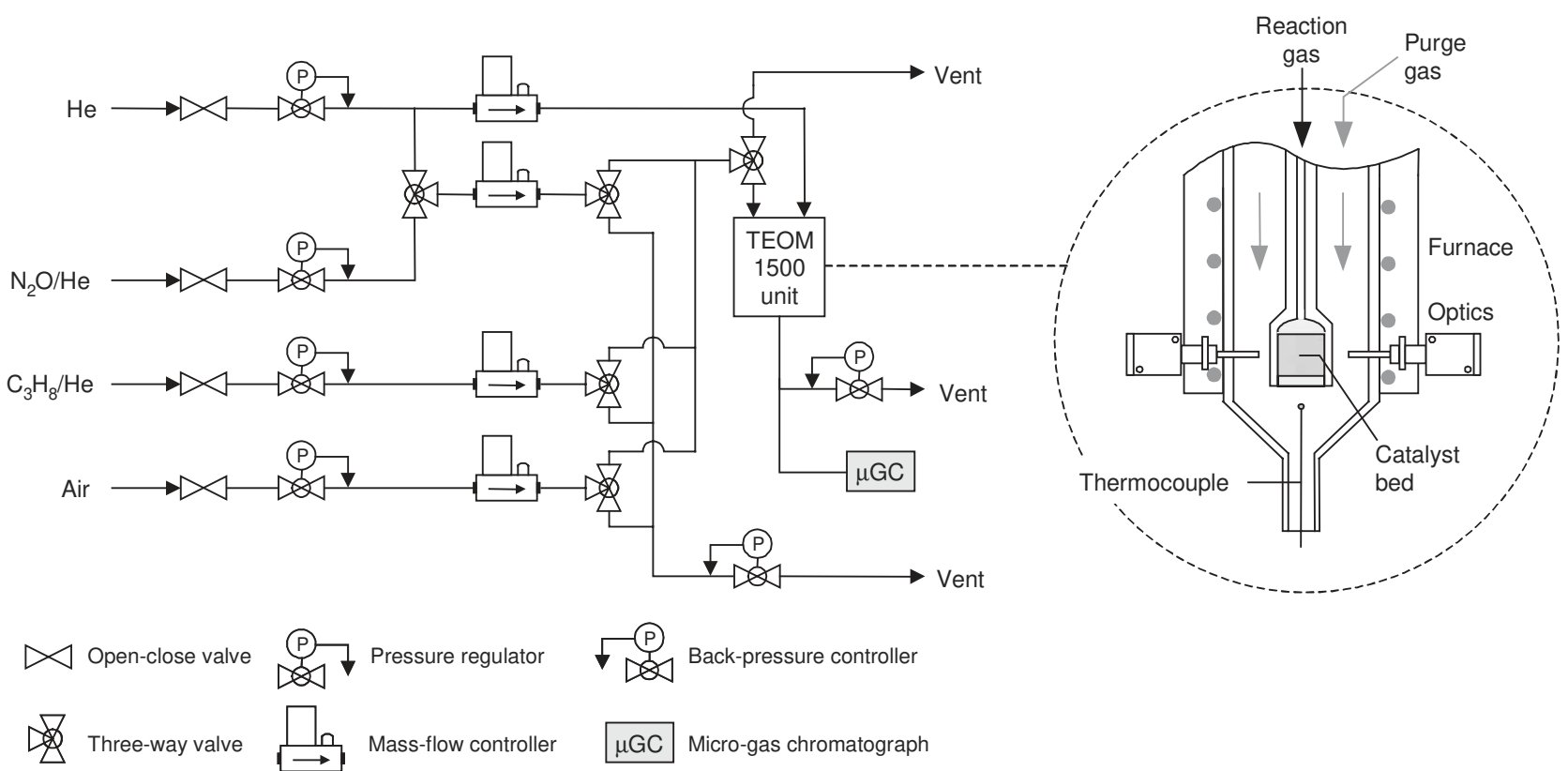

Fig. 1. Flow sheet of the TEOM set-up with a detail of the oscillating tapered element of the microbalance.

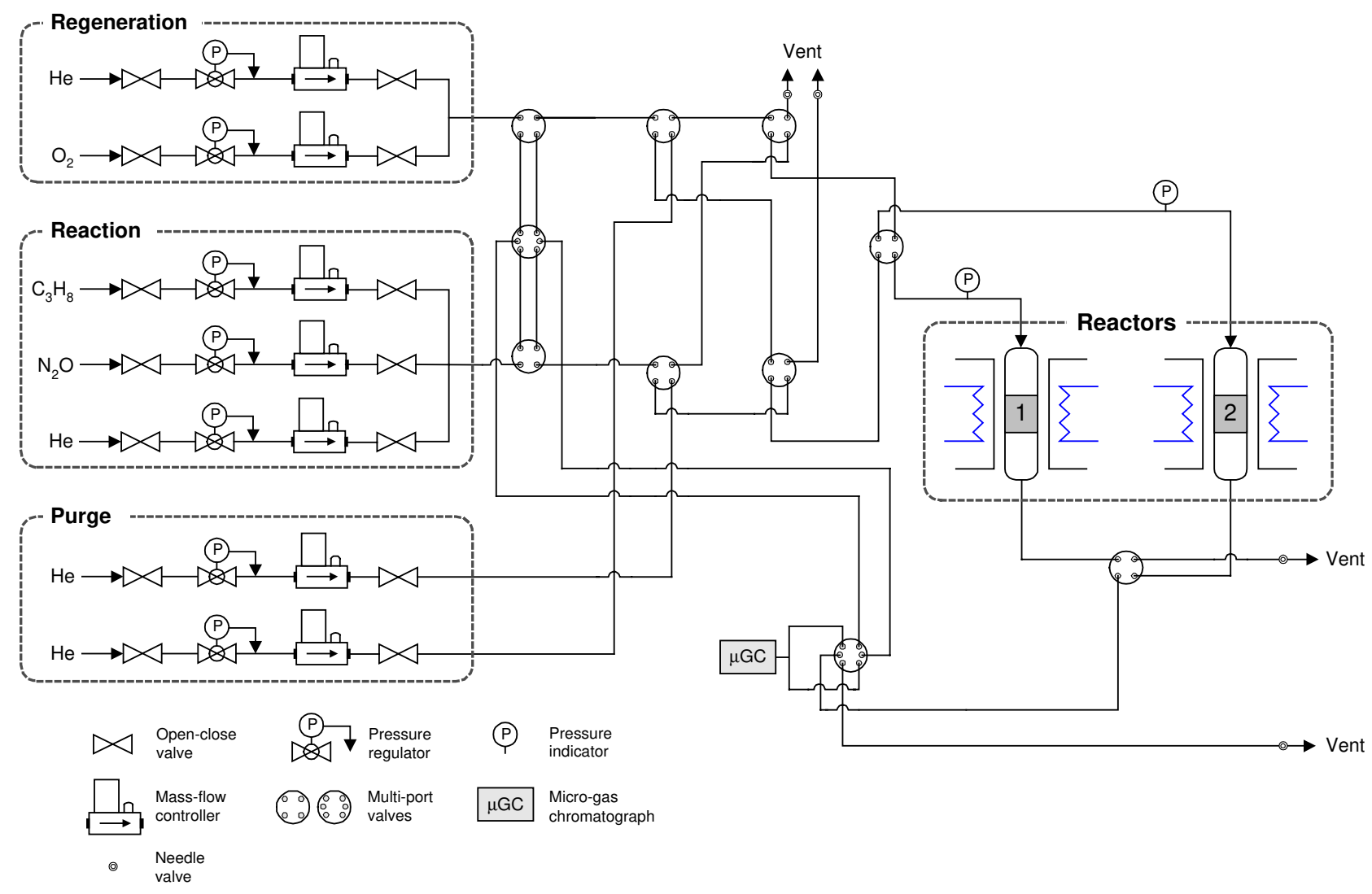

Fig. 2. Flow sheet of the set-up for cyclic experiments.

(a) temperature-programmed oxidation (TPO) in air, ramping the temperature from 298 to $973 \mathrm{~K}$ at $10 \mathrm{~K} \mathrm{~min}^{-1}$, and (b) isothermal oxidation, switching from $\mathrm{He}$ to air at a certain temperature in the range of $773-823 \mathrm{~K}$. TPO experiments require subtraction of a reference run with the uncoked zeolite under the same conditions in order to correct for the mass change caused by the variation of gas density with temperature. In isothermal regeneration, the mass change was 

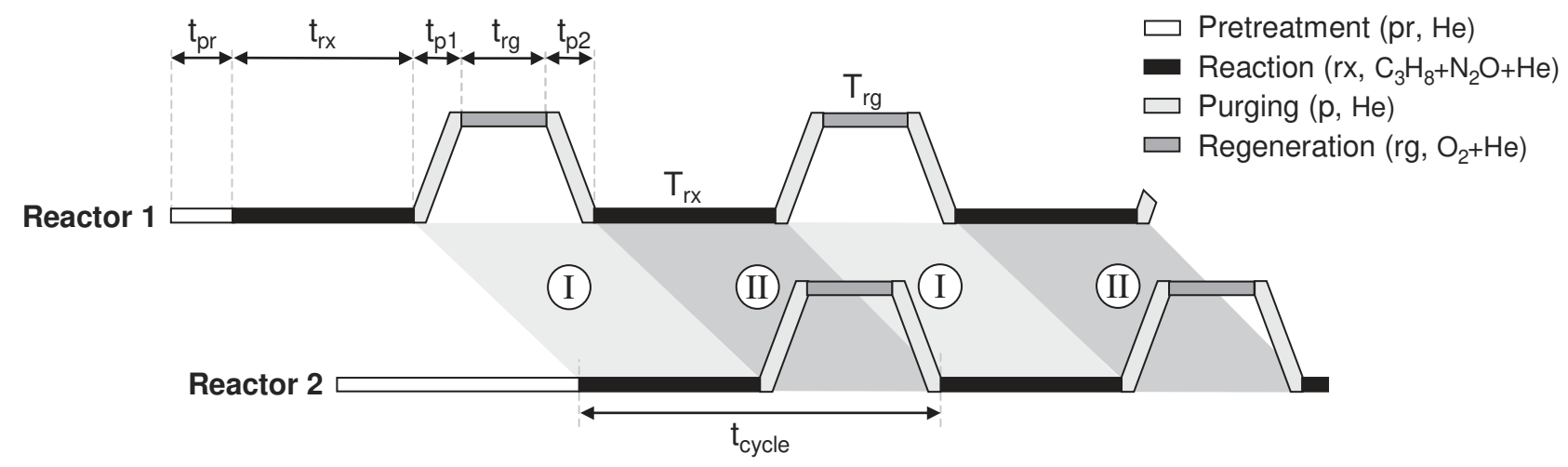

(I)

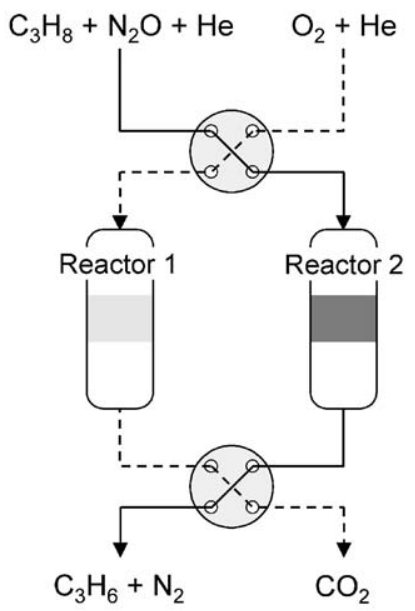

Coked catalyst
(II)

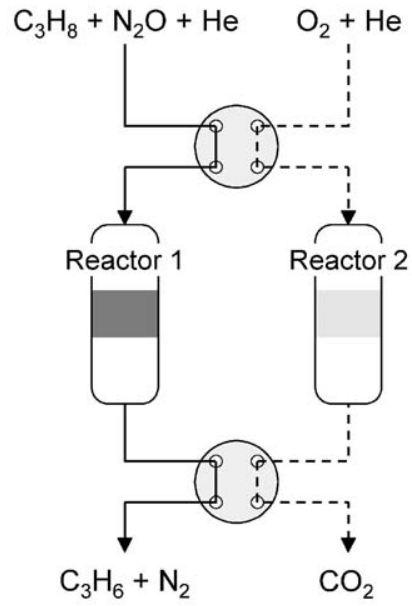

Regenerated catalyst

Fig. 3. Typical sequence in the cyclic experiments and sketch of two reactors in parallel with alternation of reaction and regeneration steps.

corrected by the change in density upon replacing the inert gas by air.

\subsection{Cyclically-operated reactor}

Cyclic experiments for continuous propene production were carried out in the set-up shown in Fig. 2, which basically consists of three feed sections: purge $(\mathrm{He})$, reaction $\left(\mathrm{N}_{2} \mathrm{O}+\mathrm{C}_{3} \mathrm{H}_{8}\right.$ in $\left.\mathrm{He}\right)$, and regeneration $\left(\mathrm{O}_{2}+\mathrm{He}\right)$, and two parallel fixed-bed quartz reactors $(4 \mathrm{~mm}$ i.d.) with independent feed and temperature control. The feed section to each reactor can be selected by means of an arrangement of multi-port valves and a sequence of cycles can be fully programmed. Cyclic experiments were conducted according to the pattern in Fig. 3. After catalyst pretreatment in flowing $\mathrm{He}$ at the reaction temperature $\left(\mathrm{T}_{\mathrm{rx}}\right)$, the reaction mixture was fed to reactor 1 . When the catalyst in this reactor deactivates after a period of $t_{\mathrm{rx}}$, the reaction mixture was switched to reactor 2 and the temperature in reactor 1 was increased to $\mathrm{T}_{\mathrm{rg}}$ in He. Once this temperature was reached and stabilized, a mixture of $20 \mathrm{vol} \% \mathrm{O}_{2}$ in $\mathrm{He}$ was intro- duced for catalyst regeneration during a period of $t_{\mathrm{rg}}$. Afterwards, the temperature in reactor 1 was decreased to $T_{r x}$ and a new reaction step was initiated. This completes one cycle $\left(\mathrm{t}_{\text {cycle }}=\mathrm{t}_{\mathrm{rx}}+\mathrm{t}_{p 1}+\mathrm{t}_{\mathrm{rg}}+\mathrm{t}_{p 2}\right)$, which is successively repeated. In order to ensure continuous production of propene, the above steps were synchronized so that the reactor 2 is under reaction during regeneration and purging of reactor 1 and vice versa (see sketches in Fig. 3). This can be fulfilled if $\left[\mathrm{t}_{\mathrm{rx}}\right]_{\text {reactor } 1}=\left[\mathrm{t}_{p 1}+\mathrm{t}_{\mathrm{rg}}+\mathrm{t}_{p 2}\right]_{\text {reactor } 2}$. The conditions applied in these tests were the same as in the TEOM experiments. Micro-GC analysis (Agilent QUADH) monitored the gas effluent from the catalytic reactor under reaction.

\section{Results and discussion}

\subsection{Performance of iron zeolites in $O D H P$ with $\mathrm{N}_{2} \mathrm{O}$}

Fig. 4 shows the coke content and propene yield with time on stream during ODHP with $\mathrm{N}_{2} \mathrm{O}$ at $723 \mathrm{~K}$ over steamactivated Fe-zeolites, as derived from the TEOM experiments and coupled gas chromatographic analysis. Reaction 

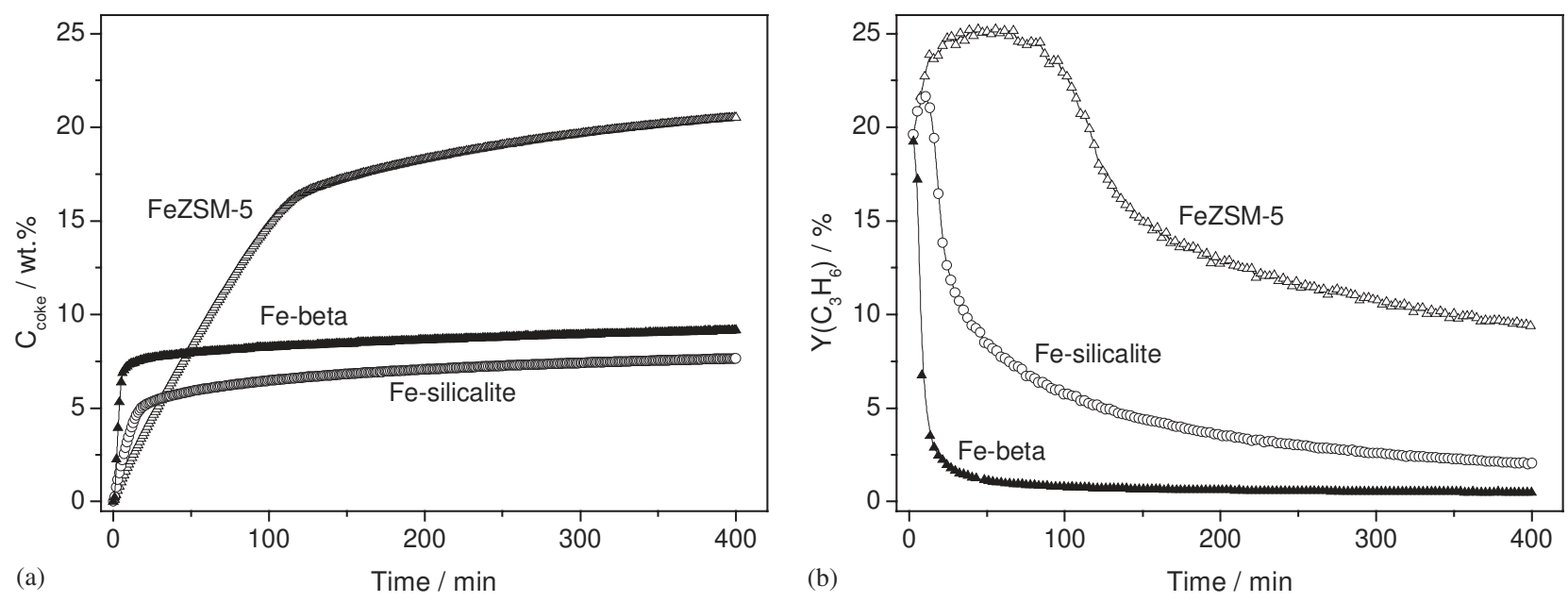

Fig. 4. Coke content and $\mathrm{C}_{3} \mathrm{H}_{6}$ yield vs. time during ODHP with $\mathrm{N}_{2} \mathrm{O}$ over steam-activated Fe-zeolites at $723 \mathrm{~K}$. Conditions: $100 \mathrm{mbar} \mathrm{C}_{3} \mathrm{H}_{8}$ and $100 \mathrm{mbar}_{2} \mathrm{O}$ in $\mathrm{He}$, WHSV $=400,000 \mathrm{ml} \mathrm{h}^{-1} \mathrm{~g}_{\text {cat }}^{-1}$, and $\mathrm{P}=2$ bar.

data after 2 min on stream (denoted as initial, $\mathrm{t}_{\mathrm{o}}$ ) and after 400 min on stream (denoted as residual or final, $\mathrm{t}_{f}$ ) are summarized in Table 1. The initial performance of the steam-activated iron zeolites was similar, regardless of the host, the acidic properties of the zeolite, and the different form(s) of extraframework iron species (Pérez-Ramírez and Gallardo-Llamas, 2004). Initial propene yields in the range of $19-22 \%$ at $723 \mathrm{~K}$ were achieved, with a similar degree of propane conversion (ca. $45 \%$ ) and propene selectivity (ca. 50\%), and complete $\mathrm{N}_{2} \mathrm{O}$ conversion. Other important reaction products were $\mathrm{CO}_{2}$ and propionaldehyde, and small concentrations of $\mathrm{CO}, \mathrm{C}_{2} \mathrm{H}_{4}, \mathrm{C}_{2} \mathrm{H}_{6}, \mathrm{CH}_{4}$, acrolein, and acetone were also detected. The interaction of $\mathrm{C}_{3} \mathrm{H}_{8}$ with the iron zeolites in the absence of $\mathrm{N}_{2} \mathrm{O}$ did not lead to propene production, indicating the essential role of the oxygen species from $\mathrm{N}_{2} \mathrm{O}$ for propane dehydrogenation.

The rate of deactivation strongly differs among the zeolites studied, decreasing in the order: Fe-beta $>$ Fe-silicalite $>$ FeZSM-5. An excellent correlation is obtained between the increase of coke content and the decrease of propene yield with time on stream. This strongly suggests that coke formation is responsible for catalyst deactivation, causing poisoning of active iron species or pore blockage. The yield of propene over Fe-beta rapidly decreases during the first $5 \mathrm{~min}$ on stream and is completely deactivated after $50 \mathrm{~min}$, with a subsequent plateau in the coking profile. The rate deactivation of Fe-silicalite is significantly reduced, which is coupled with the more gradual increase of the coke content. FeZSM-5 exhibits a remarkable resistance towards deactivation, showing an increase in propene yield from 22 to $25 \%$ during the first $20 \mathrm{~min}$ on stream. This high $\mathrm{C}_{3} \mathrm{H}_{6}$ yield is maintained during $75 \mathrm{~min}$, whilst Fe-silicalite or Fe-beta were severely or completely deactivated after this period on stream. In addition, a residual propene yield of $8 \%$ was obtained over FeZSM-5 after 400 min on stream. The different deactivation behaviour of the various iron zeolites cannot be satisfactorily explained at this stage. The behaviour of FeZSM-5 points to the presence of active iron sites with different sensitivity for coke deactivation. In general, the sudden drop of the propylene yield takes place at a characteristic time for each zeolite and coincides with a decreased slope of the coking profile, reflecting a lower rate of coke formation. Coke formation originates from polymerization and dehydrogenation (condensation) of propene, the main olefin formed over all the catalysts investigated. Ethylene concentrations in the product gas were 15 times lower than propylene. These reactions leave a layer of highly hydrogen deficient carbonaceous material on the catalyst surface, making the active sites inaccessible. Accordingly, the amount of coke should give an indication of the catalyst efficiency towards ODHP. In agreement with this, the final coke content in FeZSM-5 was ca. 3 times higher than in Fe-silicalite and Fe-beta.

The influence of the reaction temperature on the catalytic performance and time-scale for deactivation was investigated over FeZSM-5 (Table 1 and Fig. 5). The initial $\mathrm{N}_{2} \mathrm{O}$ conversion and $773 \mathrm{~K}$ increases from $76 \%$ at $673 \mathrm{~K}$ to $100 \%$ at $723 \mathrm{~K}$, while the increase in $\mathrm{C}_{3} \mathrm{H}_{8}$ conversion is much less pronounced (from $40 \%$ to $50 \%$ ) and does not increase further at $773 \mathrm{~K}$. The initial and residual conversion of reactants at 723 and $773 \mathrm{~K}$ was very similar and does not increase further at $773 \mathrm{~K}$. Although the initial (20-22\%) and residual propene yields (7-10\%) showed no significant differences, the rate of deactivation is reduced with an increase in temperature. At $773 \mathrm{~K}$, a propene yield $>20 \%$ was preserved during $200 \mathrm{~min}$, in contrast to the rapid deactivation at $698 \mathrm{~K}(10 \mathrm{~min})$. In all cases, the decrease of propene yield is coupled with the decrease of $\mathrm{C}_{3} \mathrm{H}_{8}$ and $\mathrm{N}_{2} \mathrm{O}$ conversions. The inflection point in the coking profiles at the time of the drop of the propene yield at 673 and $723 \mathrm{~K}$ was not observed at $773 \mathrm{~K}$, where the slower decrease of propene yield is coupled with a more gradual increase of the coke amount. The final amount of coke at 723 and $773 \mathrm{~K}$ is comparable, being 4 times higher than at $673 \mathrm{~K}$. The lower rate of 

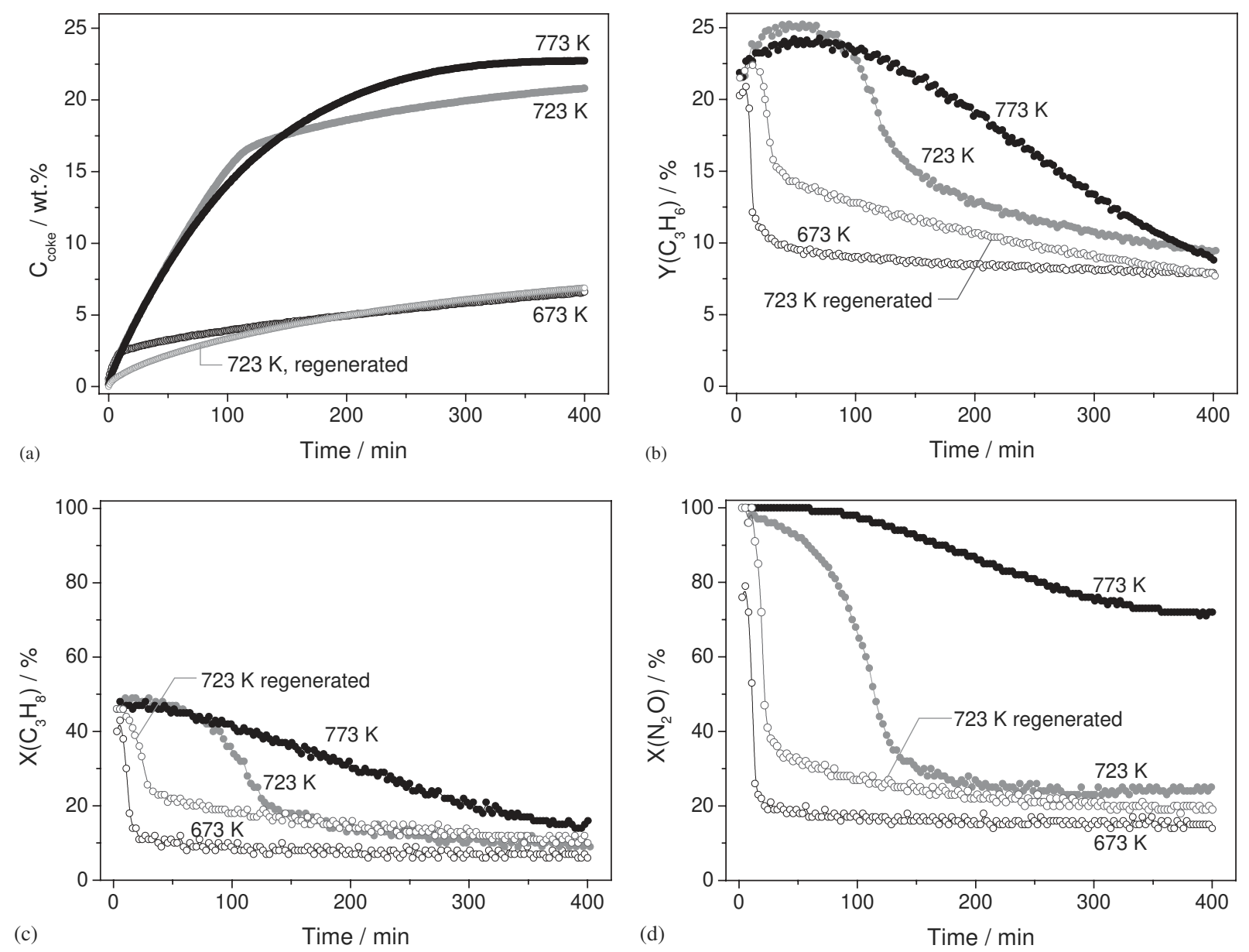

Fig. 5. Influence of the reaction temperature on the performance and deactivation behaviour of steam-activated FeZSM-5 during ODHP with $\mathrm{N}_{2} \mathrm{O}$ : (a) coke content, (b) $\mathrm{C}_{3} \mathrm{H}_{6}$ yield, (c) $\mathrm{C}_{3} \mathrm{H}_{8}$ conversion, and (d) $\mathrm{N}_{2} \mathrm{O}$ conversion. Conditions as in caption of Fig. 4.

deactivation at $773 \mathrm{~K}$ is associated with the high degree of $\mathrm{N}_{2} \mathrm{O}$ conversion, showing a residual degree of conversion of $75 \%$ as compared to $25 \%$ and $15 \%$ at 723 and $673 \mathrm{~K}$, respectively. Upon $\mathrm{N}_{2} \mathrm{O}$ decomposition, adsorbed atomic oxygen or desorbed $\mathrm{O}_{2}$ participates, at least partially, in the regeneration of the zeolite surface by oxidation of coke. This was supported by the analysis of $\mathrm{CO}_{2}$ at the reactor outlet (not shown). Ivanov et al. (2003) have concluded that $\mathrm{N}_{2} \mathrm{O}$ shows a higher activity in coke oxidation than $\mathrm{O}_{2}$ for regeneration of coke deposits in FeZSM-5 during the selective oxidation of benzene to phenol with $\mathrm{N}_{2} \mathrm{O}$.

\subsection{Regeneration of coked zeolites}

Catalyst deactivation due to coke formation poses the problem of catalytic activity restoration, which is commonly reached via oxidative treatment of coke catalyst with air or oxygen-containing mixtures at high temperatures. Temperature-programmed oxidation (TPO) as well as isothermal oxidation experiments in air were carried out in order to determine the optimal regeneration conditions (temperature and duration) of the coke-deactivated zeolites.
The inset in Fig. 6 shows the weight loss during TPO experiments over FeZSM-5 after ODHP reaction at $723 \mathrm{~K}$ for $400 \mathrm{~min}$. Coke oxidation occurs in the temperature range of $650-900 \mathrm{~K}$, and the derivative of the weight loss shows a maximum at $795 \mathrm{~K}$ and a shoulder at slightly higher temperature. With these data, isothermal regeneration in the temperature range of $723-823 \mathrm{~K}$ can be applied to further establish the duration of the regeneration step. The coke conversion vs. time characteristics in Fig. 6 were obtained over FeZSM-5 having the same initial coke amount (20wt.\%, after ODHP at $723 \mathrm{~K}$ for $400 \mathrm{~min}$ ). In good agreement with TPO results, regeneration at $823 \mathrm{~K}$ is extremely fast, with a total conversion of coke in ca. $2 \mathrm{~min}$. The time needed for complete combustion of coke is significantly increased at a lower temperature, requiring ca. 50 and $100 \mathrm{~min}$ at 773 and $723 \mathrm{~K}$, respectively.

\subsection{Performance of regenerated zeolites}

The results presented so far have been obtained over fresh zeolite catalysts. It is important to analyse the catalytic performance after various reaction and regeneration runs in 


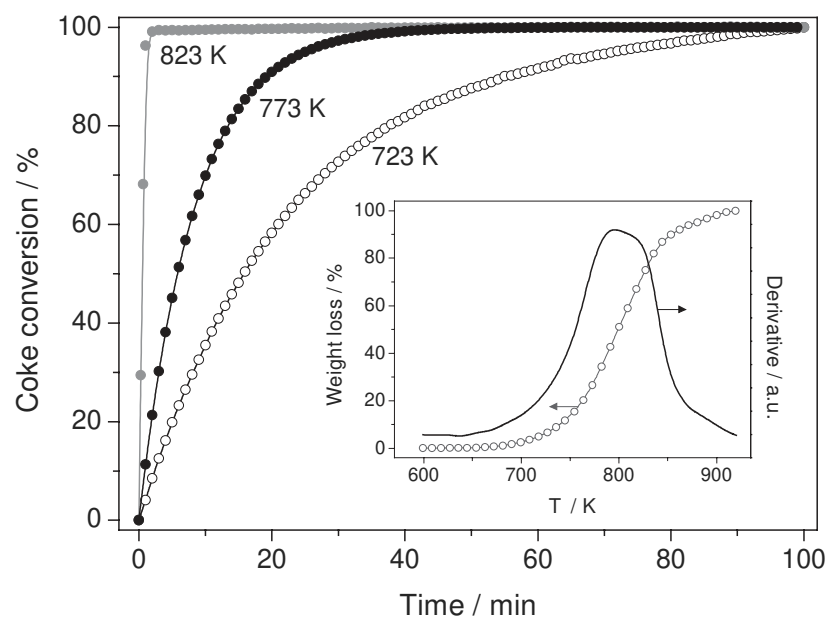

Fig. 6. Coke conversion vs. time during regeneration of deactivated FeZSM-5 (after ODHP with $\mathrm{N}_{2} \mathrm{O}$ at $723 \mathrm{~K}$ for $400 \mathrm{~min}$ ) in air at different temperatures. Conditions: WHSV $=400,000 \mathrm{ml} \mathrm{h}^{-1} \mathrm{~g}_{\text {cat }}^{-1}$, and $\mathrm{P}=2$ bar. The inset shows the weight loss profile during TPO experiments $\left(\mathrm{ramp}=10 \mathrm{~K} \mathrm{~min}^{-1}\right)$ and its derivative.

the TEOM with the same zeolite sample. The ODHP performance of regenerated FeZSM- 5 at $723 \mathrm{~K}$ is shown in Fig. 5. This sample was obtained after reaction at $723 \mathrm{~K}$ during $400 \mathrm{~min}$, followed by a temperature ramp in $\mathrm{He}$ to $823 \mathrm{~K}$ $\left(10 \mathrm{~K} \mathrm{~min}^{-1}\right)$, air-regeneration at $823 \mathrm{~K}$ for $5 \mathrm{~min}$, and cooling in $\mathrm{He}$ to $723 \mathrm{~K}\left(10 \mathrm{~K} \mathrm{~min}^{-1}\right)$. In agreement with previous observations (Pérez-Ramírez and Kondratenko, 2003), the initial performance is completely recovered after regeneration. However, the regenerated catalyst deactivates much faster than the fresh one, with a final amount of coke 4 times lower in the regenerated catalyst. Remarkably, the residual propylene yield over fresh and regenerated FeZSM-5 is very similar. This behaviour was observed at regeneration temperatures in the range of $723-823 \mathrm{~K}$. The performance of regenerated FeZSM-5 was reproducible in subsequent reaction-regeneration steps (10 cycles were performed), so the catalyst is apparently stabilized after the first cycle, which induces certain irreversible changes in the catalyst.

Catalyst deactivation is a complex process, which may be caused by a series of various phenomena. In the simplest case, according to Moulijn et al. (2001), catalyst deactivation can be caused by: (i) a decrease in the number of active sites, (ii) a decrease in the quality of the active sites, (iii) a decrease of accessibility of the pore space. The initial and residual propene yield levels over FeZSM-5 were very similar, suggesting that the number of active sites in the beginning of the reaction and in steady-state conditions is not reduced in the regenerated samples. However, the different dynamics of deactivation may be related to a fraction of the active species which is more susceptible towards deactivation or which is not participating in the reaction due to a reduced accessibility. A detailed characterization of the spent and regenerated zeolites, as well as the mechanism, nature, and location of coke formation is required to further assess the deactivation mechanism, as well as to design measures to maintain the remarkable stability of the fresh FeZSM-5 catalyst in the first period of the ODHP reaction.

\subsection{Cyclic experiments for continuous propylene production}

The best action to decrease the rate of coke deactivation is to tailor catalyst properties such as active phase, the texture, the diffusion length, and reaction conditions (Moulijn et al., 2001). Following the results of Chaki et al. (2003), addition of $\mathrm{O}_{2}$ in the feed may minimize or even suppress the formation of carbonaceous deposits in the reaction of $\mathrm{C}_{2} \mathrm{H}_{4}$ and $\mathrm{N}_{2} \mathrm{O}$ over FeZSM-5. Previous studies have concluded that the $\mathrm{ODH}$ of propane with $\mathrm{O}_{2}$ leads to low $\mathrm{C}_{3} \mathrm{H}_{6}$ yields $(<5 \%)$ (Nowińska et al., 2003; Kondratenko and Pérez-Ramírez, 2004), which further highlights the specificity of $\mathrm{N}_{2} \mathrm{O}$ as monooxygen donor in the ODHP reaction over Fe-zeolites. We have investigated the effect of adding a relatively low oxygen amount to the reaction mixture $\left(\mathrm{C}_{3} \mathrm{H}_{8} / \mathrm{N}_{2} \mathrm{O} / \mathrm{O}_{2} / \mathrm{He}=5 / 5 / 1 / 89\right)$ over Fe-silicalite at $723 \mathrm{~K}$. The initial $\mathrm{C}_{3} \mathrm{H}_{8}$ conversion was very similar than in $\mathrm{C}_{3} \mathrm{H}_{8} / \mathrm{N}_{2} \mathrm{O} / \mathrm{He}=5 / 5 / 90$ (ca. $40 \%$ ), but the $\mathrm{C}_{3} \mathrm{H}_{6}$ selectivity decreased from $52 \%$ to $30 \%$ (in favour of $\mathrm{CO}_{x}$ production). Accordingly, a low initial propylene yield (12\%) is obtained in the presence of $\mathrm{O}_{2}$, as a consequence of cracking and combustion of reaction intermediates leading to propene.

Alternatively, chemical reaction engineering solutions can be applied to restore the catalyst activity, using dedicated reactors with catalyst moving from a reaction zone and a regeneration zone. There is a relation between time-scale of deactivation and choice of reactor (Moulijn et al., 2001; Gembicki et al., 2003). In this manuscript the feasibility of a process for continuous propylene production has been demonstrated in a cyclically-operated reactor with two fixedbed reactors in parallel (Fig. 2). In view of the rapid deactivation of Fe-beta and Fe-silicalite, FeZSM-5 is the only candidate to realistically evaluate the cyclic process. Fig. 7 clearly shows that propene yields $>20 \%$ can be maintained over FeZSM- 5 during 2000 min by alternation of the reaction and regeneration cycles. The parameters of the sequence in Fig. 3 were selected based on the TEOM experiments described above. Particularly for the example in Fig. 7, reaction was carried out at $T_{\mathrm{rx}}=723 \mathrm{~K}$ for $\mathrm{t}_{\mathrm{rx}}=25 \mathrm{~min}$. The duration of the regeneration step was $25 \mathrm{~min}$ and includes the combustion of coke at $\mathrm{T}_{\mathrm{rg}}=823 \mathrm{~K}$ for $\mathrm{t}_{\mathrm{rg}}=5 \mathrm{~min}$ as well as the steps for conditioning the reactor temperature between reaction and regeneration steps $\left(\mathrm{t}_{p 1}+\mathrm{t}_{p 2}=20 \mathrm{~min}\right)$. With these settings, reaction and regeneration can be effective coupled to ensure continuous propene production at the desired yield. The cycle duration is then $50 \mathrm{~min}$ ( 40 cycles are shown in Fig. 7). This novel catalytic process can be economically applied in tail-gases of specific chemical processes, e.g. those using $\mathrm{HNO}_{3}$ as oxidizing agent, where $\mathrm{N}_{2} \mathrm{O}$ is produced in high concentration (typically $25-40 \mathrm{vol} \%$ ). 


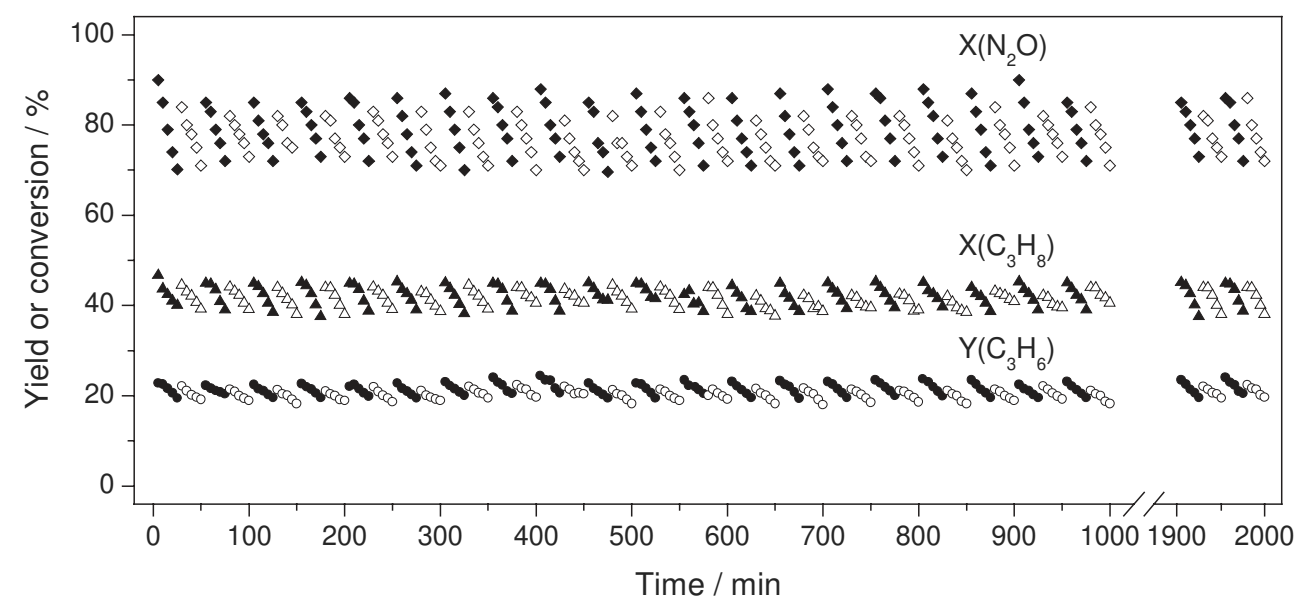

Fig. 7. Performance of steam-activated FeZSM-5 during ODHP with $\mathrm{N}_{2} \mathrm{O}$ in the cyclic process. Solid and open symbols correspond to reactors 1 and 2 , respectively. Sequence parameters (see Fig. 3): $\mathrm{T}_{\mathrm{rx}}=723 \mathrm{~K}, \mathrm{~T}_{\mathrm{rg}}=823 \mathrm{~K}, \mathrm{t}_{\mathrm{rx}}=25 \mathrm{~min}, \mathrm{t}_{\mathrm{rg}}=5 \mathrm{~min}$, and $\mathrm{t}_{p 1}+\mathrm{t}_{p 2}=20$ min. Other experimental conditions for reaction and regeneration steps as in caption of Figs. 4 and 6, respectively.

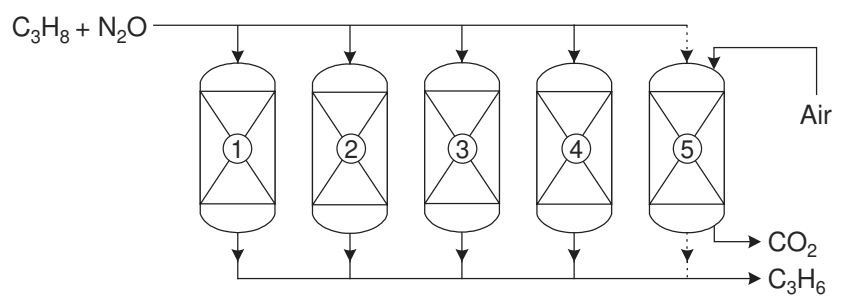

Fig. 8. Battery of parallel fixed-bed reactors for continuous propene production via $\mathrm{N}_{2} \mathrm{O}$-mediated propane oxidative dehydrogenation over Fe-zeolites. Reaction takes place in reactors $1-4$ and regeneration in reactor 5 .

In practical terms, it would be preferable to apply equal reaction and regeneration temperatures. This cannot be achieved with only two reactors in parallel, since a complete catalyst regeneration at $723 \mathrm{~K}$ will require $100 \mathrm{~min}, 4$ times longer than the reaction period of $25 \mathrm{~min}$, and thus effective coupling for continuous propene production cannot be accomplished. This can be overcome with a battery of parallel reactors (Fig. 8). This configuration is based on the cyclic Catofin process (Lummus) for non-oxidative dehydrogenation of alkanes into isobutylene, propylene, and amylenes over $\mathrm{Cr}_{2} \mathrm{O}_{3} / \mathrm{Al}_{2} \mathrm{O}_{3}$ catalysts, where three to eight fixed-bed reactors in parallel are alternatively on stream for reaction and off stream for regeneration by coke burn-off (Badoni et al., 1996; Moulijn et al., 2001). In this process, the cycle time between reaction and regeneration mode is typically between 10 and $30 \mathrm{~min}$. This process integrates part of the heat during regeneration (exothermic) in the reaction (endothermic). In our case, however, both reaction and regeneration processes are exothermic, which is less optimal from a heat management standpoint. Other reactor configurations, commercially applied in alkane dehydrogenation, include radial-flow moving-bed reactors connected in series (Oleflex, UOP), fluidized-bed reactor with regenerator (FBD-4, Snamprogetti), or multiple fixed-bed tubular re- actor in a firebox (STAR, Philips). Different engineering options are possible for the same problem, depending on factors such as choice of catalyst, relation between chosen process conditions and catalyst deactivation, and company experience.

\section{Conclusions}

A cyclically-operated process for continuous production of propylene via ODHP with $\mathrm{N}_{2} \mathrm{O}$ over steam-activated iron zeolites has been developed. Fe-zeolites are highly efficient catalysts for the oxidative dehydrogenation of propane using $\mathrm{N}_{2} \mathrm{O}$, with initial propene yields in the range of $20-25 \%$ at $723-773 \mathrm{~K}$, but they deactivate due to coke formation. The deactivation process is strongly influenced by the zeolite host and the reaction temperature. TEOM studies were essential to correlate activity and deactivation by simultaneous measurements of reaction and coking, as well as to appraise catalyst regeneration. This information was used to rationally design the reaction and regeneration sequences in the cyclic process. The continuous propene production via a cyclically-operated process was demonstrated over FeZSM-5, where propene yields $>20 \%$ were achieved during a period of $2000 \mathrm{~min}$, in a configuration of two fixed-bed reactors in parallel with alternation of reaction (at $723 \mathrm{~K}$ ) and regeneration (at $823 \mathrm{~K}$ ) cycles. This novel catalytic process leads to the simultaneous functionalization of $\mathrm{C}_{3} \mathrm{H}_{8}$ and utilization of $\mathrm{N}_{2} \mathrm{O}$.

\section{Acknowledgements}

Dr. A. Grønvold is gratefully acknowledged for assistance in the TEOM experiments and Dr. E.V. Kondratenko for fruitful discussions. 


\section{References}

Badoni, R.P., Kumar, Y., Shanker, U., Rao, T.S.R.P., 1996. Emerging technologies for light olefins productions. Chemical Engineering World $31,105-110$.

Buyevskaya, O.V., Baerns, M., 2002. Oxidative functionalization of ethane and propane. Catalysis 16, 155-197 and references therein.

Chaki, T., Arai, M., Ebina, T., Shimokawabe, M., 2003. Catalytic reduction of $\mathrm{N}_{2} \mathrm{O}$ by $\mathrm{C}_{2} \mathrm{H}_{4}$ over Fe-ZSM-5: formation and nature of carbonaceous deposits and influence of the addition of $\mathrm{O}_{2}$. Journal of Catalysis 218, 220-226.

Chen, D., Rebo, H.P., Moljord, K., Holmen, A., 1996. Effect of coke deposition on transport and adsorption in zeolites studied by a new microbalance reactor. Chemical Engineering Science 51, 2687-2692.

Gembicki, S.A., VandenBussche, K.M., Oroskar, A.R., 2003. Novel tools to speed up the technology commercialization process. Chemical Engineering Science 58, 549-555.

Ivanov, D.P., Sobolev, V.I., Panov, G.I., 2003. Deactivation by coking and regeneration of zeolite catalysts for benzene-to-phenol oxidation. Applied Catalysis A. General 241, 113-121.

Kondratenko, E.V., Pérez-Ramírez, J., 2004. Oxidative functionalization of propane over FeMFI zeolites. Effect of reaction variables and catalyst constitution on the mechanism and performance. Applied Catalysis A. General 267, 181-189.

Liu, Y., Wang, J., Zhou, J.G., Xian, M., Bi, Y., Zhen, K., 2001. Oxidative dehydrogenation of propane to propene over barium promoted Ni-Mo-O catalyst. Reaction Kinetics and Catalysis Letters 73, 199-208.

Moulijn, J.A., van Diepen, A.E., Kapteijn, F., 2001. Catalyst deactivation: is it predictable? What to do?. Applied Catalysis A. General 212, 3-16.
Nowińska, K., Wącław, A., Izbińska, A., 2003. Propane oxydehydrogenation over transition metal modified zeolite ZSM-5. Applied Catalysis A. General 243, 225-236.

Pak, C., Bell, A.T., Don Tilley, T., 2002. Oxidative dehydrogenation of propane over vanadia-magnesia catalysts prepared by thermolysis of $\mathrm{OV}\left(\mathrm{O}^{t} \mathrm{Bu}\right)_{3}$ in the presence of nanocrystalline $\mathrm{MgO}$. Journal of Catalysis 206, 49-59.

Pérez-Ramírez, J., Gallardo-Llamas, A., 2004. $\mathrm{N}_{2} \mathrm{O}$-mediated propane oxidative dehydrogenation over steam-activated iron zeolites. Journal of Catalysis 223, 382-388.

Pérez-Ramírez, J., Kondratenko, E.V., 2003. Steam-activated FeMFI zeolites as highly efficient catalysts for propane and $\mathrm{N}_{2} \mathrm{O}$ valorization via oxidative conversions. Chemical Communications 2152-2153.

Pérez-Ramírez, J., Mul, G., Kapteijn, F., Moulijn, J.A., Overweg, A.R., Ribera, A., Arends, I.W.C.E., 2002. Physicochemical characterization of isomorphously substituted FeZSM-5 during activation. Journal of Catalysis 207, 113-126.

Pérez-Ramírez, J., Kapteijn, F., Groen, J.C., Doménech, A., Mul, G., Moulijn, J.A., 2003. Steam-activated FeMFI zeolites Evolution of iron species and activity in direct $\mathrm{N}_{2} \mathrm{O}$ decomposition. Journal of Catalysis $14,33-45$.

Tullo, A.H., 2003. Propylene on demand. Chemical and Engineering News $81(50), 15-16$

Watson, R.B., Ozkan, U.S., 2000. K/Mo catalysts supported over sol-gel silica-titania mixed oxides in the oxidative dehydrogenation of propane. Journal of Catalysis 191, 12-29.

Zhu, W., van de Graaf, J.M., van den Broeke, L.J.P., Kapteijn, F., Moulijn, J.A., 1998. TEOM: a unique technique for measuring adsorption properties. Light alkanes in silicalite-1. Industrial and Engineering Chemistry Research 37, 1934-1942. 